\title{
Pembelajaran Mood, Understand, Recall, Detect, ElaboRATE, AND REVIEW (MURDER) BERBASIS PROYEK DALAM PEMBELAJARAn Matematika
}

\author{
MOOD, UNDERSTAND, RECALL, DETECT, ELABORATE, AND REVIEW (MURDER) \\ LEARNing BASED Project In MATHEMATICAL LEARNing
}

\author{
Tina Sri Sumartini \\ Program Studi Pendidikan Matematika, STKIP Garut \\ Garut, Jawa Barat, Indonesia \\ tina.srisumartini@gmail.com
}

\begin{abstract}
Abstrak
Pelaksanaan pembelajaran matematika perlu dilakukan dengan tepat agar siswa memiliki kemampuan berpikir tingkat tinggi. Salah satu metode pembelajaran yang bisa digunakan adalah Mood, Understand, recall, Detect, Elaborate, and Review (MURDER). Pelaksanaan pembelajaran ini diawali dengan membangun suasana hati siswa agar memiliki perasaan dan pemikiran positif terhadap matematika, memahami materi matematika, mengingat kembali materi yang telah dipelajari, Mendeteksi kesalahan yang dilakukan, mengelaborasi pengetahuan, dan mengulas kembali apa yang telah dikerjakan. Agar pembelajaran lebih bermakna, dalam pembelajaran MURDER perlu disertai pelaksanaan suatu proyek yang berkaitan dengan materi yang dibahas. Proyek yang dimaksud dapat berupa pengamatan dan pengkajian terhadap fenomena dalam lingkungan sekitar yang berkaitan dengan materi yang sedang dibahas.

Kata Kunci: Pembelajaran MURDER, Pembelajaran Berbasis Proyek.
\end{abstract}

\begin{abstract}
Implementation of mathematics learning needs to be done properly so that students have highlevel thinking skills. One of the learning methods that can be used is Mood, Understand, Recall, Detect, Elaborate, and Review (MURDER). Implementation of this learning begins by building the mood of students to have positive feelings and thoughts about mathematics, understand mathematical material, recall the material that has been studied, detect mistakes made, elaborate knowledge, and review what has been done. For learning to be more meaningful, in learning MURDER needs to be accompanied by the implementation of a project related to the material discussed. The project in question can be observation and assessment of phenomena in the surrounding environment related to the material being discussed.

Keyword: MURDER Learning, Project Based Learning.
\end{abstract}

\section{Pendahuluan}

Matematika merupakan pelajaran yang dapat meningkatkan ketajaman berpikir. Hal ini dapat dilihat dari bentuk materi dan juga penyajiaan soal-soal yang membutuhkan daya nalar yang tinggi. Oleh karena itu, dalam pembelajaran matematika, siswa perlu dilatih untuk memiliki kemampuan berpikir tingkat tinggi.

Dilihat dari struktur konten, pembelajaran matematika terkesan serius. Namun, perlu suatu upaya untuk 
mencairkan suasana agar pembelajaran matematika dapat menyenangkan. Hal utama yang perlu dilakukan adalah menghidupkan mood siswa agar menyenangi matematika. Selanjutnya, siswa akan tergerak untuk mempelajari matematika yang pada akhirnya dapat memahami dan mampu berpikir matematis.

Dalam pelaksanaan pembelajaran matematika memerlukan suatu metode pembelajaran yang relevan. Salah satu metode pembelajaran yang bisa digunakan dalam pembelajaran matematika adalah pembelajaran Mood, Understand, Recall, Detect, Elaborate, dan Review (MURDER). Pada metode pembelajaran ini, diawali dengan membangun mood siswa agar memiliki perasaan positif terhadap matematika, memahami materi, menggunakan kembali materi yang telah dipelajari, memeriksa kembali pengetahuan yang telah dimiliki, mengelaborasi pengetahuan, dan mengulas kembali apa yang telah dikerjakan. Agar pembelajaran lebih bermakna, dalam pembelajaran MURDER perlu disertai pelaksanaan suatu proyek yang berkaitan dengan materi yang dibahas. Proyek yang dimaksud dapat berupa pengamatan dan pengkajian terhadap setiap fenomena dalam lingkungan sekitar.

Berdasarkan hal tersebut, perlu dilakukan kajian teori mengenai pelaksanaan pembelajaran MURDER berbasis proyek dalam pembelajaran matematika dan bagaimana contoh penyajian materinya.

\section{KAJIAN TEORI}

MURDER terdiri dari enam kata yaitu Mood, Understand, Recall, Detect, Elaborate, dan Review. Pembelajaran MURDER pertama kali dimunculkan oleh Dansereau et al pada tahun 1979 sebagai salah satu bentuk pembelajaran kooperatif (Lambiotte, Judith et al, 1987). Mood berarti menetapkan pola pikir dan suasana hati yang positif untuk belajar, understand berarti memahami apa yang sedang dipelajari, Recall berarti memanggil kembali pengetahuan yang telah diingat, detect berarti memeriksa kembali kebenaran dan menemukan kesalahannya, elaborate berarti mengelaborasi pengetahuan, dan review berarti mengulas kembali apa yang telah dikerjakan. Pembelajaran MURDER dapat membangun motivasi siswa dan memberikan kesempatan kepada siswa untuk belajar mandiri melalui kegiatan memaknai materi dan berdiskusi (Hasanah, U \& Kartono, 2016)

Pada tahap mood, guru membangun suasana hati yang positif dalam diri siswa. Proses ini merupakan tahap awal guru dalam memenangkan hati siswa agar mau belajar matematika dan mengikuti setiap tahap pembelajaran. Dengan suasana hati yang baik siswa akan mampu mengoptimalkan kemampuannya sehingga dapat mencapai prestasi yang diharapkan. Perasaan menyenangkan dan tidak menyenangkan dalam situasi akademik 
mempengaruhi prestasi siswa (Dettmers et al., 2011).

Tahap understand, siswa harus bisa memahami apa yang sedang dipelajari. Pada tahap ini guru perlu memberikan stimulus penjelasan materi matematika secara tertulis misalkan dengan bahan ajar atau media yang lainnya sehingga siswa bisa belajar mandiri dan mengembangkan persepsinya terhadap apa yang dia baca. Selanjutnya, siswa melakukan tahap recall berarti memanggil kembali pengetahuan yang telah diingat. Tahap ini juga perlu difasilitasi oleh guru dengan memberikan berbagai pertanyaan baik secara langsung maupun melalui pemberian LKS. Siswa yang mengikuti pembelajaran MURDER berbantuan LKS memiliki hasil belajar yang tinggi (Ariningsih, Sarni, \& Suranata, 2013)

Tahap Detect berarti memeriksa kembali kebenaran dan menemukan kesalahannya. Tahap ini bisa dilakukan dengan melakukan diskusi sehingga siswa dapat mencermati serta menganalisis hasil pemecahan masalah yang diberikan. Dengan proses ini dapat diketahui berbagai kesalahan yang dilakukan sehingga pemahaman konsep dapat lebih optimal.

Pada tahap Elaborate berarti mengelaborasi pengetahuan,.Selain itu, siswa akan bersemangat untuk melaksanakan projek yang akan ditugaskan oleh guru. Berdasarkan kurikulum 2013, pembelajaran perlu ditekankan pada pembuatan projek sehingga siswa dapat lebih memahami materi yang diajarkan. Pembelajaran berbasis proyek merupakan suatu pembelajaran yang menyangkut pemusatan pertanyaan dan masalah yang bermakna, pemecahan masalah, pengambilan keputusan, proses pencarian berbagai sumber, pemberian kesempatan kepada anggota untuk bekerja secara kolaborasi, dan menutup dengan presentasi produk nyata (Thomas, 2000). Pelaksanaan pembelajaran berbasis proyek dimulai dengan pemberian masalah untuk merangsang kognitif mahasiswa berupa pengintergrasian berbagai pengetahuan yang dimilikinya. Dari permasalahan tersebut akan diperoleh suatu konsep baru yang aplikasinya dapat dibuat sebuah proyek berupa karya tulis atau media pembelajaran matematika. Palaksanan pembelajaran ini dilakukan secara berkelompok dengan tujuan untuk menggabungkan berbagai ide untuk membuat suatu proyek yang inovatif. Kelebihan pembelajaran ini yaitu: 1) otentik konstektual yang akan memperkuat hubungan antara aktivitas dan pengetahuan konseptual yang dimiliki oleh mahasiswa; 2) mengedepankan otonomi pembelajaran dan dosen sebagai pembimbing dan mitra belajar; 3) belajar kolaboratif yang memberikan peluang untuk saling membelajarkan; 4) realistik, yaitu berorientasi pada belajar aktif memecahkan masalah real yang berkontribusi pada peningkatan kemampuan kognitif mahasiswa; 5) memberikan umpan balik internal yang 
dapat meningkatkan kemapuan kogniti dan afektif mahasiswa.

Langkah-langkah pembelajaran berbasis proyek yaitu; 1) perencanaan proyek, 2) pelaksanaan proyek; 3) penyelidikan terbimbing dan pembuatan produk; 4) kesimpulan proyek (Mergendoller, et,al,. 2006). Pembelajaran berbasis projek dapat memotivasi siswa untuk belajar dan menerapkan matematika sehingga siswa dapat aktif dalam proses memenuhi masalah, mengidentifikasi kebutuhan, menentukan masalah dan berbagi informasi, menghasilkan solusi yang terbaik (Remijan, 2016). Dalam pembelajaran berbasis projek, guru harus mampu menciptakan lingkungan belajar yang menghubungkan satu proyek ke proyek yang lainnya, mendorong sifat inovatif siswa, memotivasi siswa untuk melakukan suatu proyek.

Terakhir tahap review berarti mengulas kembali apa yang telah dikerjakan. Tahap ini dilakukan dengan membuat rangkuman sebagai cara untuk mematangkan pemahaman siswa.

\section{Pembahasan}

Pembelajaran MURDER berbasis proyek bisa digunakan dalam pembelajaran matematika. Adapun langkah-langkah pembelajarannya adalah sebagai berikut:

Tabel 1.

Aktivitas Pembelajaran MURDER Berbasis Proyek

\begin{tabular}{|c|c|}
\hline Langkah & Aktivitas Pembelajaran \\
\hline Mood (Mengatur Suasana Hati) & $\begin{array}{l}\text { 1. Pemberian motivasi mengenai kebermaknaan pembelajaran } \\
\text { 2. Pembentukan kelompok yang terdiri dari 3-4 siswa secara } \\
\text { heterogen }\end{array}$ \\
\hline $\begin{array}{l}\text { Understand (Membaca untuk } \\
\text { memahami) }\end{array}$ & $\begin{array}{l}\text { 1. Pembagian bahan ajar kepada siswa } \\
\text { 2. siswa membaca bahan ajar }\end{array}$ \\
\hline Recall (Mengingat Kembali) & $\begin{array}{l}\text { 1. Pembagian LKS yang berisi soal-soal yang berkaitan dengan materi } \\
\text { yang sudah dibaca dalam bahan ajar } \\
\text { 2. Setiap kelompok mengerjakan LKS }\end{array}$ \\
\hline Detect (Menemukan Kesalahan) & $\begin{array}{l}\text { 1. Salah satu kelompok untuk mempresentasikan hasil diskusinya } \\
\text { 2. Kelompok lain untuk mencermati apa yang sedang dipresentasikan } \\
\text { dan menuliskan kesalahan yang dilakukan dalam prses pengerjaan } \\
\text { LKS serta ketidakcocokan dengan konsep materi yang sedang } \\
\text { dibahas }\end{array}$ \\
\hline $\begin{array}{l}\text { Elaborate (mengelaborasi } \\
\text { pengetahuan) }\end{array}$ & $\begin{array}{l}\text { 1. Kelompok lain untuk menyampaikan argumennya mengenai } \\
\text { jawaban yang sedang dipresentasikan sehingga terjadi diskusi } \\
\text { 2. Siswa untuk membuat contoh lain mengenai materi yang telah } \\
\text { dipelajari } \\
\text { 3. Guru membagikan rancangan projek yang harus dibuat siswa dan } \\
\text { dikumpulkan pada pertemuan berikutnya }\end{array}$ \\
\hline Review (mengulang kembali) & $\begin{array}{l}\text { Guru bersama siswa melakukan refleksi dan membuat kesimpulan dari } \\
\text { materi yang telah dipelajari }\end{array}$ \\
\hline
\end{tabular}


Pelaksanaan pembelajaran matematika dari kurikulum 2013. Keterkaitannya dapat dengan MURDER perlu diintegrasikan dilihat dalam tabel berikut. dengan pendekan saintifik sebagai bagian

Tabel 2.

Integrasi Pendekatan Saintifik dengan Pembelajaran MURDER Berbasis Projek

\begin{tabular}{|c|c|c|}
\hline $\begin{array}{c}\text { Tahap MURDER Berbasis } \\
\text { Projek }\end{array}$ & Pendekatan Saintifik & Keterangan \\
\hline $\begin{array}{l}\text { Mood (Mengatur Suasana } \\
\text { Hati) }\end{array}$ & Menanya & $\begin{array}{l}\text { Siswa mendengarkan motivasi } \\
\text { guru dan menjawab pertanyaan } \\
\text { guru. }\end{array}$ \\
\hline $\begin{array}{l}\text { Understand (Membaca } \\
\text { untuk memahami) }\end{array}$ & Mengumpulkan informasi & $\begin{array}{l}\text { Siswa menerima bahan ajar dari } \\
\text { guru dan membacanya untuk } \\
\text { memahami materi yang akan } \\
\text { dipelajari }\end{array}$ \\
\hline Recall (Mengingat Kembali) & Mengumpulkan Informasi & $\begin{array}{l}\text { Siswa menerima LKS dari guru } \\
\text { mengingat kembali materi yang } \\
\text { sudah dibaca dari bahan ajar dan } \\
\text { mulai mengerjakan LKS }\end{array}$ \\
\hline $\begin{array}{ll}\text { Detect } & \text { (Menemukan } \\
\text { Kesalahan) }\end{array}$ & Mengamati dan Mengkomunikasikan & $\begin{array}{l}\text { Siswa mempresentasikan hasil } \\
\text { diskusinya dan saling mencermati } \\
\text { hasil presentasi dengan konsep } \\
\text { materi yang sedang dibahas }\end{array}$ \\
\hline $\begin{array}{l}\text { Elaborate (mengelaborasi } \\
\text { pengetahuan) }\end{array}$ & Mengasosiasi & $\begin{array}{l}\text { Siswa membuat contoh lain } \\
\text { mengenai materi yang telah } \\
\text { dipelajari dan menerima tugas } \\
\text { pembuatan projek yang berkaitan } \\
\text { dengan materi yang sudah } \\
\text { dipelajari }\end{array}$ \\
\hline Review (mengulang kembali) & Mengumpulkan informasi & $\begin{array}{l}\text { Siswa bersama guru melakukan } \\
\text { refleksi dan membuat kesimpulan } \\
\text { dari materi yang telah dipelajari }\end{array}$ \\
\hline
\end{tabular}

Adapun contoh pelaksanaan pembelajaran MURDER dalam pembelajaran matematika adalah sebagai berikut:

\section{Contoh Penerapan Pembelajaran MURDER Berbasis Projek dalam Materi Luas Jajar Genjang}

Tahap 1: Mood
1. Guru masuk ke dalam kelas dengan mengucapkan salam, tersenyum, dan menyapa dengan penuh kasih.

2. Guru bersama siswa berdo'a bersama-sama

3. Guru memberikan motivasi baik dengan bercerita atauyang lainnya

4. Guru menyampaikan judul materi yang akan disampaikan dan 
menceritakan ilustrasi pentingnya mempelajarinya

5. Guru membentuk kelompok sebanyak 3-4 siswa setelah heterogen. Pembentukan kelompok telah dipersiapkan oleh guru sebelumnya berdasarkan nilai pada materi sebelumnya

Tahap 2: Understand

1. Guru membagikan bahan ajar mengenai luas permukaan kubus dan balok.

2. Guru meminta siswa untuk membaca dan memahami isi bahan ajar tersebut

Contoh bahan ajar

Langkah-langkah:

1. Sediakan alat tulis, penggaris, busur, karton, dan jarum pentul berwarna

2. Tancapkan dua jarum pentul secara sejajar ke pinggir pada karton dengan jarak $10 \mathrm{~cm}$. Hubungkan kedua jarum tersebut dengan spidol dan beri nama ujungnya dengan $A$ dan B.

3. Tancapkan kembali dua jarum pentul di bawah kedua jarum pentul tadi dengan jarak $10 \mathrm{~cm}$

4. Geserkan kedua jarum pentul yang berada di bawahnya ke arah kanan sebesar $4 \mathrm{~cm}$. Hubungkan kedua jarum tersebut dengan spidol dan beri nama ujungnya dengan $C$ dan $D$

5. Hubungkan ujung garis $A$ dengan $C$ dan ujung garis $B$ dengan $D$

6. Dengan cara yang sama, buatlah bidang lain dengan nama dan ukuran yang berbeda
Lengkapi gambar-gambar yang telah dibuat dengan:

1. Besar sudut yang terbentuk

2. Ukuran panjang garis

3. Tandai garis-garis yang sejajar

\section{Pengamatan:}

Amati bagaimana besar sudut, panjang garis, dan garis-garis berhadapan pada masing-masing jajar genjang. Tuliskan pengamatanmu pada kotak di bawah ini.

\begin{tabular}{|c|c|c|c|}
\hline $\begin{array}{l}\text { Ga } \\
\text { m } \\
\text { ba } \\
r\end{array}$ & $\begin{array}{l}\text { Sudut } \\
\text { Berhadapa } \\
\text { n }\end{array}$ & $\begin{array}{l}\text { Panjang } \\
\text { Garis }\end{array}$ & $\begin{array}{l}\text { Posisi garis } \\
\text { berhadapa } \\
\text { n }\end{array}$ \\
\hline 1 & $\begin{array}{l}\angle \ldots \text { dan } \angle \\
\angle \ldots \text { dan } \angle\end{array}$ & $\begin{array}{l}A B \\
=\cdots \mathrm{cm} \\
C D \\
=\cdots \mathrm{cm} \\
A C \\
=\cdots \mathrm{cm} \\
B D \\
=\cdots \mathrm{cm}\end{array}$ & $\begin{array}{ll}\ldots & \text { dan .. } \\
\ldots & \text { dan } . .\end{array}$ \\
\hline 2 & $\begin{array}{l}\angle \ldots \text { dan } \angle \\
\angle \ldots \text { dan } \angle\end{array}$ & $\begin{array}{l}\cdots \\
=\cdots \mathrm{cm} \\
\cdots \\
=\cdots \mathrm{cm} \\
\cdots \\
=\cdots \mathrm{cm} \\
\cdots \\
=\cdots \mathrm{cm}\end{array}$ & $\begin{array}{l}\ldots \text { dan } \\
\ldots \text { dan }\end{array}$ \\
\hline
\end{tabular}

Dengan demikian jajar genjang memiliki ciri:

1.

2.

3. 


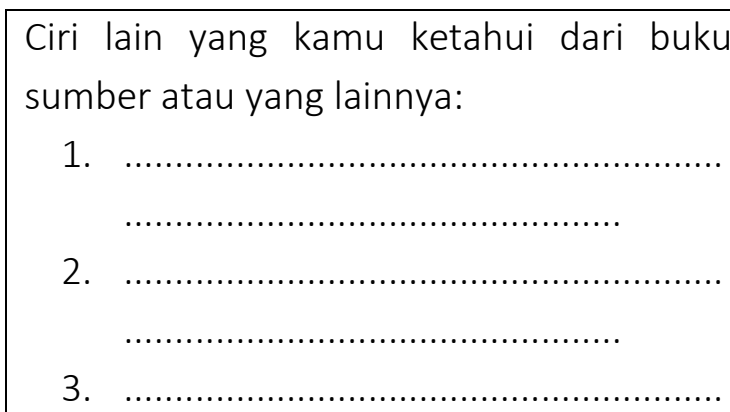

Pengertian Jajar genjang

Tuliskan pendapatmu tentang pengertian jajar genjang!

Perhatikan Gambar berikut!

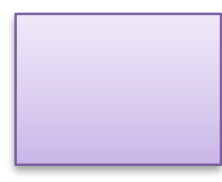

(1)

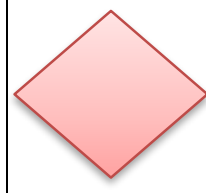

(3)

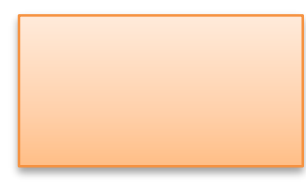

(2)

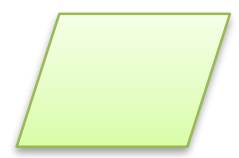

(4)

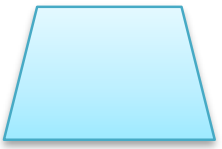

(5)
Berdasarkan pengertian jajar genjang yang kamu ketahui, mana saja gambar di atas yang merupakan jajar genjang?

Mana yang bukan merupakan jajar genjang?

Mengapa?

Diskusikan dengan teman sekelompokmu tentang pengertian jajar genjang agar lebih tepat!

Jajar genjang adalah

Tahap 3: Recall

1. Guru meminta siswa untuk membuat peta konsep mengenai luas jajar genjang berdasarkan hasil pemahaman dari bahan ajar

2. Guru membagikan LKS kepada siswa

3. Guru meminta setiap kelompok untuk berdiskusi mengerjakan LKS tersebut

Adapun permasalahan yang diberikan adalah:

Di bawah ini adalah sketsa sawah pa Aman. Ukuran sketsa tersebut adalah $P Q=20 \mathrm{~cm}, P R=13 \mathrm{~cm}$ sedangkan perbandingan panjang RO dan RS adalah $1: 4$.

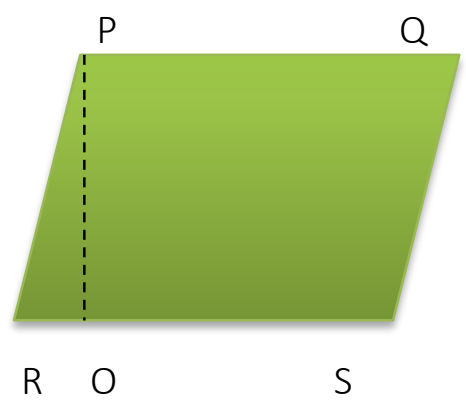

Coba kalian buat proses penyelesaian untuk mencari luas dan keliling dari sawah pa Aman tersebut!

Tahap 4: Detect

1. Guru meminta setiap kelompok mempresentasikan hasil diskusinya

2. Kelompok lain untuk mencermati apa yang sedang dipresentasikan dan 
menuliskan kesalahan yang dilakukan dalam proses pengerjaan.

Tahap 5: Elaborate

1. Guru meminta kelompok lain untuk menyampaikan argumennya mengenai jawaban yang sedang dipresentasikan sehingga terjadi diskusi

2. Guru memberikan penjelasan bila terjadi kekeliruan

3. Guru meminta siswa untuk membuat contoh lain mengenai konsep luas jajar genjang

4. Guru membagikan rancangan projek yang harus dibuat siswa dan dikumpulkan pada minggu berikutnya. Dalam pembuatan projek tersebut, setiap kelompok harus mendesain perencanaan proyek, menyusun jadwal, dan mempresentasikan hasilnya di depan kelas. Adapun rancangan proyek yang ditugaskan kepada siswa adalah:

a. Carilah dan tuliskan masingmasing 3 nama-nama benda yang berbentuk jajar genjang yang ada di lingkungan kalian!

b. Ukurlah setiap panjang sisi jajar genjang tersebut!

c. Dari hasil pengukuran tersebut, hitunglah setiap luas daerahnya!

d. Buatlah laporannya dalam bentuk makalah dan tuliskan juga kendala yang dihadapi selama pembuatan projek!

Tahap 6 : Review

Guru bersama siswa melakukan refleksi dan membuat kesimpulan dari materi yang telah dipelajari. Review yang dilakukan berupa pembuatan rangkuman mengenai konsep luas jajar genjang, menuliskan aktivitas yang sudah dilakukan selama proses pembelajaran dan menulis saran untuk bahan evaluasi pembelajaran matematika selanjutnya.

\section{Penutup}

Pembelajaran MURDER berbasis proyek terdiri dari enam tahap yaitu Mood (membangun suasana hati siswa agar memiliki perasaan dan pemikiran positif terhadap matematika), Understand (memahami materi matematika), recall (mengingat kembali materi yang telah dipelajari), Detect (mendeteksi kesalahan yang dilakukan), Elaborate (mengelaborasi pengetahuan dengan pembuatan proyek), dan Review (mengulas kembali apa yang telah dikerjakan).

\section{Daftar Pustaka}

Ariningsih, N., Sarni, N., \& Suranata, K. (2013). Pengaruh Model Pembelajaran Kooperatif Tipe MURDER.

Dettmers, S., Trautwein, U., Lüdtke, O., Goetz, T., Frenzel, A. C., \& Pekrun, R. (2011). Students ' emotions during homework in mathematics : Testing a theoretical model of antecedents and achievement outcomes. Contemporary Educational Psychology, 36(1), 25-35. https://doi.org/10.1016/j.cedpsych.20 $\underline{10.10 .001}$ 
Hasanah, U \& Kartono, W. (2016). Keefektifan Pembelajaran MURDER Berpendekatan PMRI Dengan Asesmen Kinerja Pada Pencapaian Kemampuan Literasi MatematikaSiswa SMP Serupa PISA. Unnes_Journal_of_Mathematics_Educ ation, 5.

Lambiotte, J., Dansereau, D., Rocklin, T., Fletcher, B., Hythecker, V., Larson, C., \& O’Donnell, A. (1987). Cooperative Learning and Test Taking: Transfer of Skills. Contemporary Educational Psychology, 12, 52-61.

Mergendoller, J.R, et.all., 2006. Pervasive Management of Project Based Learning: Teacher as Guided and Facilitators. Dalam Evertson, C.M \& Weinstein, C.S.(Ed), Handbook of Classroom Management Reseach, Practice dan Contemporary Issues. Lawrence Erlbaum Associates Inc. Publisher.
Remijan, K. W. (2016). Project-Based Learning and Design-Focused Projects to Motivate Secondary Mathematics Students. Interdisciplinary Journal of Problem-Based Learning, 11(1). Available at: http://dx.doi.org/10.7771/15415015.1520.

Thomas, J.W. 2000. A Review of Research on Project Based Learning. California: The Autodesk Foundation. Tersedia pada: http://www.Autodesk.com

\section{Riwayat Hidup Penulis}

\section{Tina Sri Sumartini, M.Pd.}

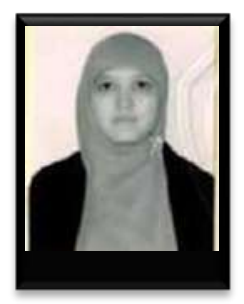

Lahir di Garut, 11 Maret 1988. Staf pengajar di STKIP Garut. Studi S1 Pendidikan Matematika STKIP Garut, lulus tahun 2010; S2 Pendidikan matematika Universitas Pendidikan Indonesia, Bandung, lulus tahun 2014. 
This page is intentionally left blank 